\title{
Defects and behaviour of inverted flat roof from the point of building physics
}

\author{
Ivan Misar $^{1 *}$ and Marek Novotný ${ }^{2}$ \\ ${ }^{1}$ A.W.A.L. s.r.o., Eliášova 20, 16000 Prague 6, Czech Republic \\ ${ }^{2}$ Faculty of Architecture, Czech Technical University, Thákurova 9, 16900 Prague 6, Czech Republic
}

\begin{abstract}
One of the most discussed flat roof structures during the last 20 years is a structure called inverted roof, where the main thermal insulation layer is placed above the main waterproofing system. The reasons why this type of flat roof is or could be chosen are more less clear. Usually it is the intention to protect the main waterproofing system, usually of synthetic or bituminous membranes, against the impact of outdoor air thermal changes, against any prospective mechanical damages and also to reduce risk of water vapor condensation in the structure. This type of structure could help to solve the vapor/thermal difficulties during the design of the flat roof over the space with higher indoor air humidity like swimming pools or specific industrial processes. Due to the higher rate of safety against mechanical damage it is also used quite often in the case of the design of the roof terraces or roof gardens. Nevertheless, the correct attitude during the design of the structure is to take into considerations all possible aspects including the defects and problems which are most typical for each one type of structure. This paper is willing to give the brief overview of the typical defects for inverted flat roofs and to contribute a little to the understanding of commonly discussed effect of undergoing water beneath the thermal insulation itself and decreasing thus the thermal protection efficiency as well as the inner surface temperature.
\end{abstract}

\section{Introduction}

The flat roof is one of structures highly affected with the external climatic conditions. Nevertheless, this structure is highly important for the durability and longevity of the building structure as a whole. One specific solution of the structure design is considered to be modern but still provoking a lot of questions. This is the solution based or related to inverted flat roofs. Composition of such structure is known. It is based on the layer of waterproofing liner, or monolithic - in-situ created from liquid applied waterproofing, or prefabricated flexible sheets, and on the layer of thermal insulation placed above the waterproofing itself. The variety is of the liner types is high. The choice of the thermal insulation is limited by the request of low water absorption. At the moment only one product could be taken as a suitable choice for thermal insulation it is extruded polystyrene board [1-8].

\footnotetext{
${ }^{*}$ Corresponding author: misar@awal.cz
} 
The crucial question which was highly discussed in the past decade is the heat loss by cold rain water going through the joints between the boards of thermal insulation itself and going towards the water outlet system beneath this insulation, respectively directly on the waterproofing. This phenomenon could even result into the decreasing of internal surface temperature below the dew point temperature and cause thus the vapour condensation on this surface. The most serious period is the snow melting period.

The public opinion presumes the main volume of rain water is going above the insulation boards. The ratio of the water undergoing the thermal insulation boards is not well defined, still.

In order to help us with the orientation in this problematic there was an experiment provided.

\section{Description of Experiment}

\subsection{Definition of Main Task}

The experiment itself was supposed to help within description and definition of the ratio of rain water undergoing the thermal insulation. Co-relation with the simulated flat roof slope, upper protective layer, either gravel ballast or paving on the sand or gravel based stabilization layer and the presence of so called water barrier was investigated.

\subsection{Consequential Tasks}

During the experiment itself a few of next questions or tasks occurred:

- to define the co-relation between the type of separation textile installed on the insulation boards,

- to describe the possibility of tightening of the extruded polystyrene board joints,

- to check the influence of joints and joint imperfections to the heat transmission of base structure by the thermo-vision inspection,

- to define the reducing coefficients (factors) of the $\mathbf{\Delta} \mathbf{U}$-value, for inverted roofs according to the slope, outlet system and rain water barrier installation on the upper thermo insulation boards surface or on any other water tightening system of joints.

\subsection{Construction of Testing Equipment}

The wooden frame and OSB structure was used to prepare two testing boards of $1 \times 2 \mathrm{~m}$ of dimensions. One should simulate the behaviour of flat roof drained by the inner gully and the second one the drainage ensured through the linear flashing on the edge of the roof.

The waterproofing was done from flexible prefabricated SBS modified bituminous membranes with the slate flakes self protection. The thermo insulation boards of extruded polystyrene of $100 \mathrm{~mm}$ of thickness were then placed into these frames. Perimeter joints were sealed with the silicone mastic in order to reach the same ratio of joints as in the reality. The AL gutter flashings were installed in the groove $1 \mathrm{~cm}$ under the upper edge of the XPS board to collect the rain, resp. artificial rain, water going above the XPS itself.

The composition above the XPS boards was variable. Gravel ballast screed on the nonabsorbing separation textile $200 \mathrm{~g} / \mathrm{m}^{2}$ or the ceramic tiles on sand screed on the same textile were installed. Consequently, the gravel ballast screed on the breathing membrane, called lately as a water barrier, was tested as well. The overlaps of this breathing membrane were loosely laid with the $20 \mathrm{~cm}$ of width or tighten by the adhesive tape. The next variant was to tighten the XPS boards joints with the compressed taped installed into the gaps. 


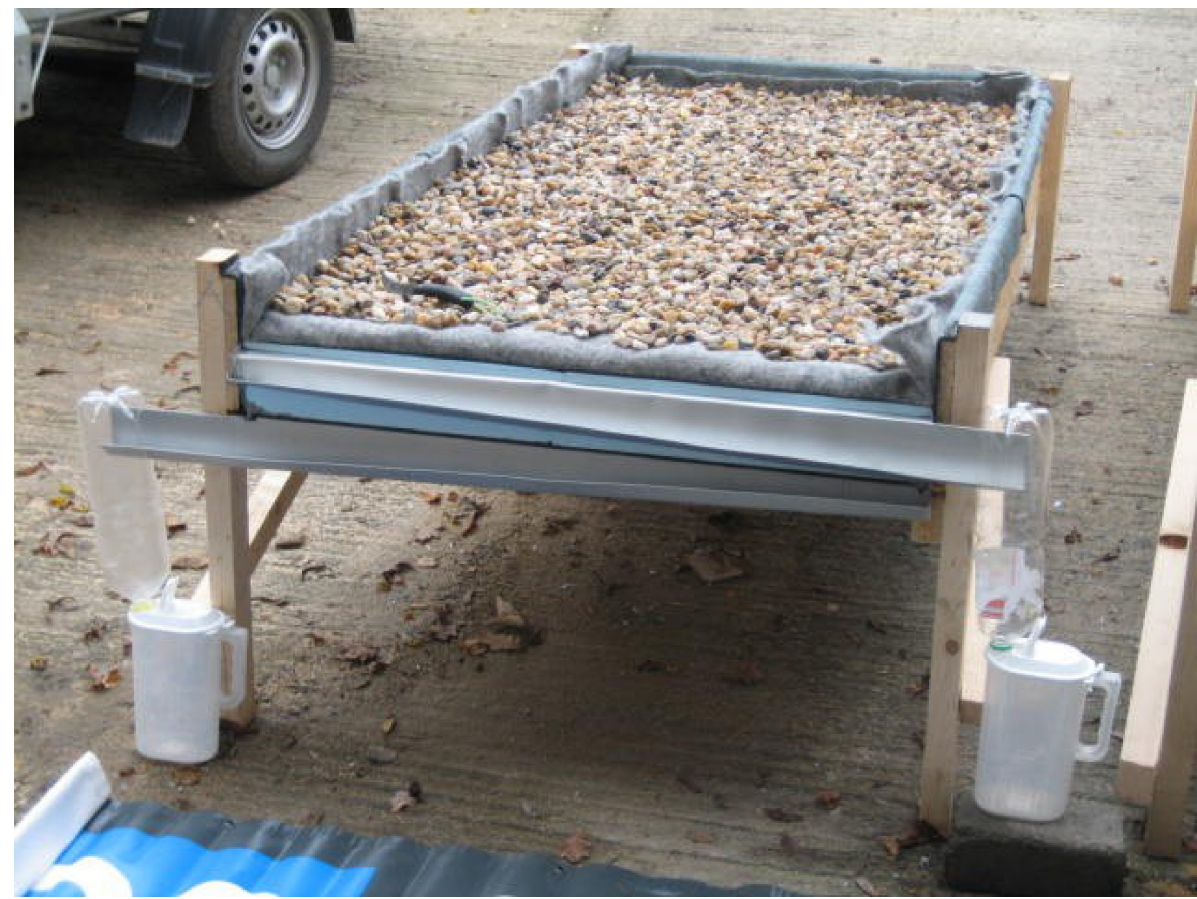

Fig. 1. Water collection system and structure - frame A (drainage through flashing simulation).

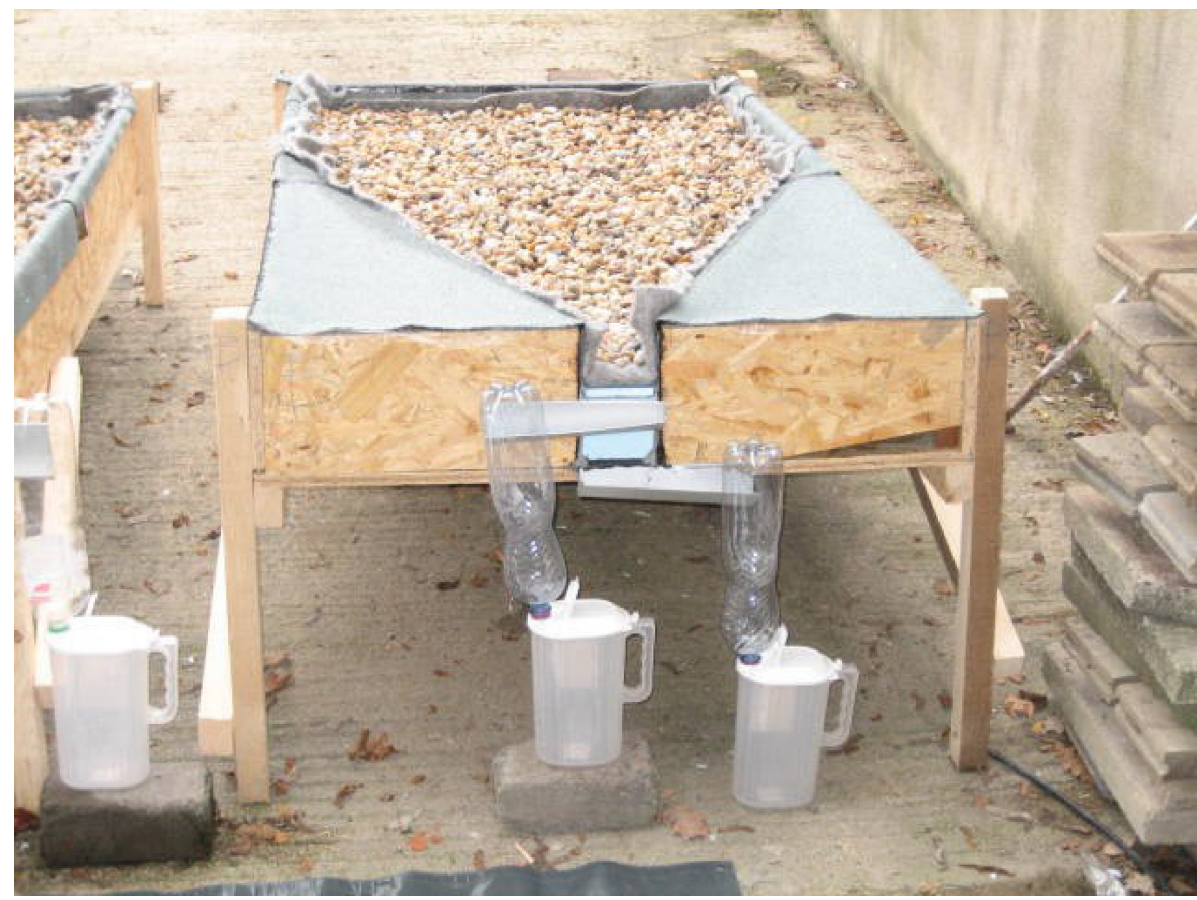

Fig. 2. Water collection system and structure - frame B (drainage through inner gully simulation). 


\section{Results}

The ratio of undergoing water in the various roof slopes in condition of artificial rain was measured. The ratio of undergoing water was on the contrary with the public opinion quite high and that it decreased within the increasing slope, depending also on the scheme of water outlet. The undergoing water flow is not steady but it concentrates around the joints of XPS boards, mainly around of those with improper installation. Thermo-vision photos are one of the evidence. It seems that approx. 50\% of undergoing water flow rather through joints. It is clear that any mathematical model would be, more less, theoretical and not fully corresponding with the reality.

The quite surprising result was reached in case of standard breathing membrane with the low $\mathrm{s}_{\mathrm{d}}-$ equivalent diffusive thickness, under $0.1 \mathrm{~m}$, placed in the position of separation layer between the XPS insulation boards and the gravel ballast layer. The results became to be nearly inverted. It seems it would be very efficient for the future to implement this result, means breather membrane installation instead of standard geo-textile one, which is quite commonly used nowadays, as separation layer, to the practice to decrease the heat loss and risk of vapour condensation on internal surface by the undergoing water. This breather membrane takes the function of certain rain water barrier in the structure. In case of indoor high air humidity, it would also slightly reduce the risk of accidental vapour condensation on the inner roof structure surface.

The moisture content by weight up to $4 \%$ was measured in the middle of XPS board, after 2.5 years of exposition and beneath the geo-textile of $300 \mathrm{~g} / \mathrm{m}^{2}$.

The measurements in the joint area were much more interesting. In these cases, the increased level of moisture was found, mostly in the layer under horizontal surface of semi lock and in the close location.

This fact can be taken as one of evidences of diffusive absorption existence in this part. Consequently, the reduction of thermal insulation efficiency with increased heat conduction coefficient by the moisture can be expected here as well.

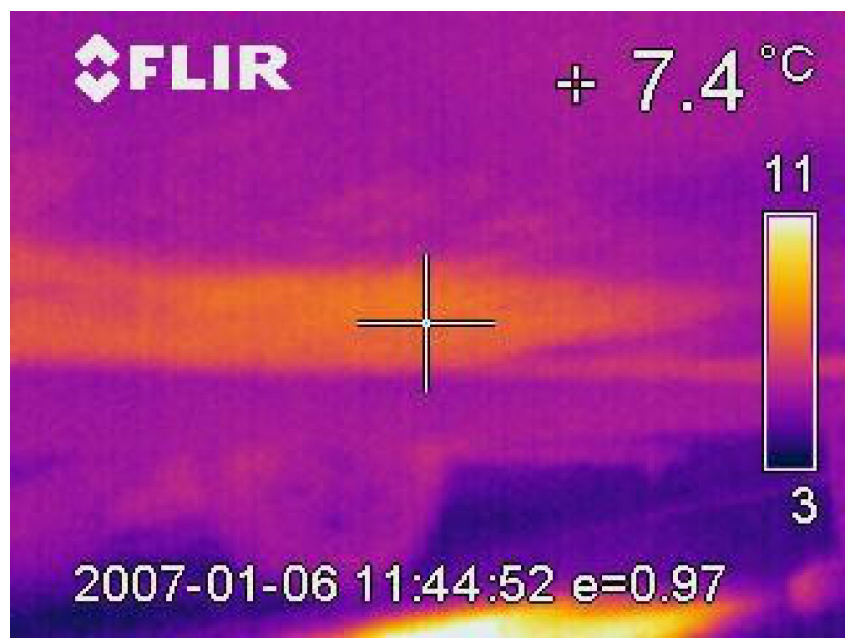

Fig. 3. Approximative surface temperature measurement at the imperfection of the joint location on frame A. 


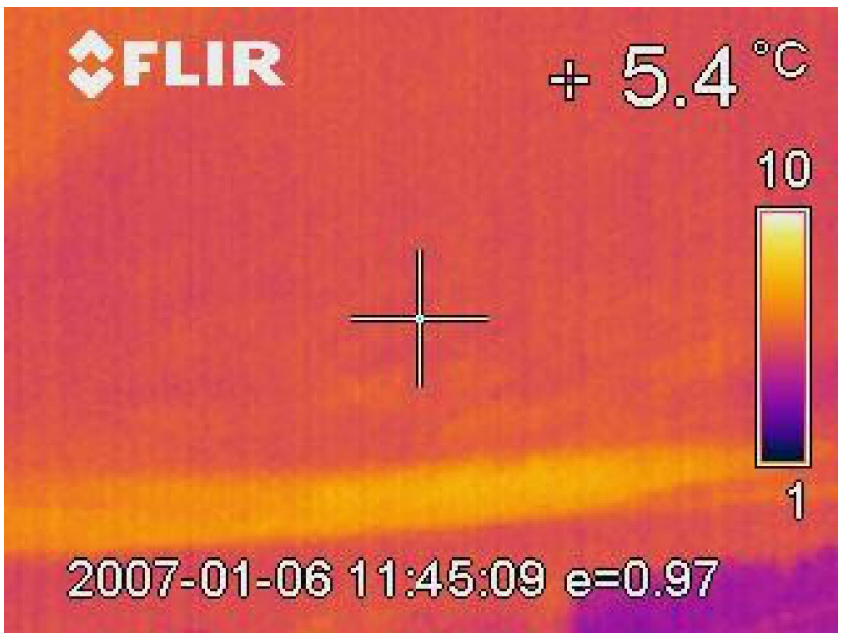

Fig. 4. Approximative surface temperature measurement at the main area of frame A.

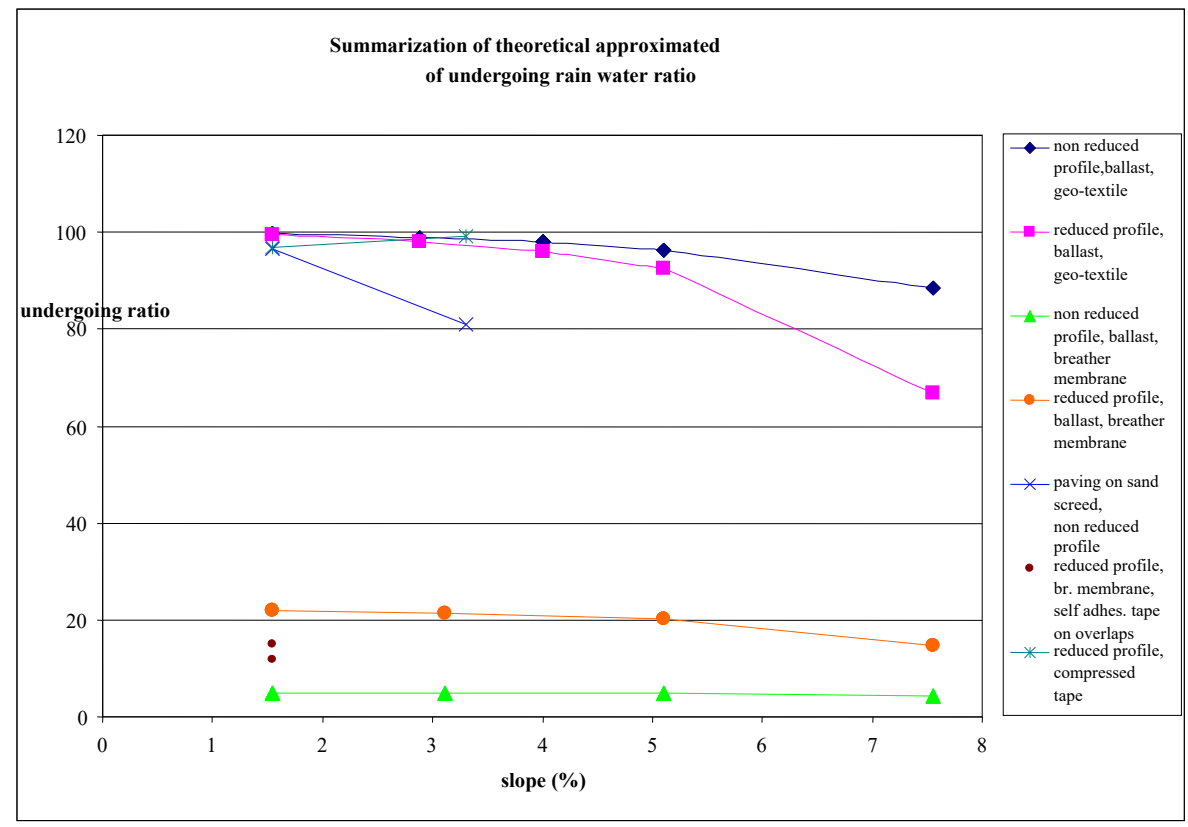

Fig. 5. Summarization of theoretical approximated functions of undergoing rain water ratio in relation with slope.

If the breather membrane will be installed instead of the standard separation geotextile we can for the results representation of the influence use the factor $\mathbf{f w}$,

for non-reduced flow profile (sample A):

$$
f w=0.05
$$

for reduced flow profile (simulation of inner gully (sample B): 


$$
f w=0.22
$$

Slope reduction coefficient could be represented by slope factor fs, expressing the ratio of undergoing water beneath the thermal insulation boards to the all rain water falling down to the roof surface in relation with slope.

for non-reduced flow profile:

$$
f_{S}=1-0.038 \cdot \sinh \left(s^{2} / 31\right)
$$

for reduced flow profile (simulation of inner gully):

$$
f_{S}=1-0.05 \cdot \sinh \left(s^{2} / 22\right)
$$

where $\quad \mathrm{s}$ is a slope of roof structure in $\%$.

These factors could be implemented as reduction coefficients for $\Delta \mathbf{U}$-value. The equation involving the slope and rain water barrier for $\Delta \mathbf{U}$-value for inverted roofs would be:

$$
\Delta U=0,04 \cdot f w \cdot f_{s} \cdot p \cdot\left(R_{l} / R\right)^{2}\left[\mathrm{~W} /\left(\mathrm{m}^{2} \cdot \mathrm{K}\right)\right]
$$

where $\quad \boldsymbol{p}$ is average rain water amount in mm/day during the heating season,

$\boldsymbol{R}_{\boldsymbol{1}}$ is thermal resistance of XPS layer above the waterproofing system,

$\boldsymbol{R}$ is common thermal resistance of structure in $\left(\mathrm{m}^{2} \cdot \mathrm{K}\right) / \mathrm{W}$

$\boldsymbol{F} \boldsymbol{w}$ is rain water barrier installation factor (breather membrane),

$f \boldsymbol{s}$ is slope factor.

\section{Conclusions}

The experiment has proved the rain water undergoing thermal insulation boards of inverted roofs is playing the significant role within the heat loss through the inverted roof structure which should be a subject of our interest for the future.

On the base of above described experiment we can realize that the influence of water barrier, made of breather membrane, will reduce the ratio of undergoing rain water many times. No significant reduction of the undergoing water ratio was measured when the seams were glued together or when the thermal insulation boards were sealed by compressed tape.

The usage of rain water barrier shall be recommended for the practice. We can still see a wide field of the application physics works for next experiments (e.g. determination of influence of breather membrane quality to the described effect).

On the base of the experiment it is able to say that the drainage of rain water in case of inverted roofs should be preferred through inner gully.

We can say on the base of co-relation between the undergoing water ratio and the type of water drainage system that the reduction of the space between the under surface of insulation boards and the waterproofing plays the role. We can dare to say we shouldn't keep this contact space more permeable for the water. Thus I can dare to suggest avoid the installation of any studded foil under the insulation boards. 


\section{References}

1. Ch. Curtoise \& coll, Practical Guide to Flat Roofing; Pitsburg Corning Europe N.V. (1999)

2. A. F. Nielsen, E. M. Paulsen, Thermal design of highly insulated inverted roofs, (Norvegian Building Research Institute, Trondheim, Norway)

3. H.M. Kunzel, K. Kiessl, Assessing Precipitation Heat Losses of Protected Membrane Roofs (Hemtie Closing Seminar, Finland 1996)

4. J.C. Beech, G.K. Saunders, The performance of Lightweight Inverted Flat Roofs, (Building Research Establishment, Princes Risborough Laboratory Buckinghamshire, UK)

5. H.M. Kunzel, K. Kiessl, Moisture Behaviour of Protected Membrane Roofs with Greenery, (Frauhofer-Institute of Building Physics)

6. K. Halahyja, B. Bet'ko, K. Bloudek, P. Tomašovič, P., J. Puškáš, Stavebná tepelná technika, akustika a osvetlenie technika (SNTL, 1985)

7. M. Novotný, I. Misar, Ploché střechy (Grada, Praha 2003)

8. V. Vymětalík, Tepelně izolační vlastnosti inverzních střech (Thermoinsulation Abilities of Inverted Roofs), (ČVUT, Prague, 2007) 